$\mathbb{T}$ periodica polytechnica

Social and Management Sciences $17 / 1$ (2009) $4 7 \longdiv { 5 5 }$

doi: 10.3311/pp.so.2009-1.05

web: http://www.pp.bme.hu/so

(c) Periodica Polytechnica 2009

RESEARCH ARTICLE

\section{Optimal selection of recourses in projects based on the classical time - cost trade - offs}

Helga Csordás

Received 2010-01-05

\begin{abstract}
Network models are often applied in project scheduling. In Time-cost Trade-offs problem time and cost parameters are assigned to the activities. It means that we have to decide the technology (recourses) will be applied. Generally there is not only one proper variant in construction practice. In this paper I generate the Time-cost Trade-offs problem based on maximal flow algorithm by integration the possibility of changing technology. In this way the algorithm will automatically select the proper technological variant for the activities.
\end{abstract}

\section{Keywords \\ CPM cost $\cdot$ technology $\cdot$ maximal flow}

\section{Helga Csordás}

Department of Construction Technology and Management, BME, $1111 \mathrm{Bu}-$ dapest, Múegyetem rkp. 3. II. 17, Hungary

e-mail: hcsordas@ekt.bme.hu

\section{Introduction}

The Time-cost Trade-offs problem gives a scheduling to the wanted deadline with minimal cost level. It was presented at first in 1959 in work of Kelley and Walker [10] in which they gave a solution based on linear programming on activity-on-edge network. In 1961 Fulkerson [3] and Kelly [9] gave another solution based on maximal flow algorithm. This problem can be originated to minimal cost flow algorithm which is in Ahuja [1]. In 1969 Klafszky [11] then in 1992 Hajdú and Klafszky [5] showed the acceleration of that. These solutions are based on maximal flow algorithm also.

This classical problem was generalized in several ways. Activity-on-node network (MPM) is applied in construction practice. The converting to this model was worked out by Hajdú [4] in 1993. In this model only minimal constraints are allowed and the activities are not split. The latter constraint was resolved by Hajdú [6].

For expanding input data Mályusz [8] examined extra charges like indemnity and premium integration in the model at milestones. Mályusz [7] deals with applying indirect cost parameters in the model. The solution is originated to the structure of classical model by splitting activities intervals with constant cost. This method can be base of many engineering problem like the work of Csordás and Mályusz [2] where different technological variants can be assigned to the activities. In this paper I show another model generating method for this problem, which makes the algorithm more efficient and simple because it does not work with regressive flows.

\section{Review of the problem}

The network for modelling projects has nodes to sign occurrences and arcs to sign activities or connections. In case of activities we can define the activity time according to the technical matter and its two extremes. Let be $b$ the normal duration as the activity time belonged to the minimal cost level and $a$ the crash duration as the possible minimal activity time. Here $a$ and $b$ are nonnegative. Let be $\tau$ the realized activity time in sheduling. Of course $a \leq \tau \leq b$. Further let be $K_{b}$ the cost level belonged to $b$ and $K_{a}$ and belonged to $a$. The cost function let be linear 


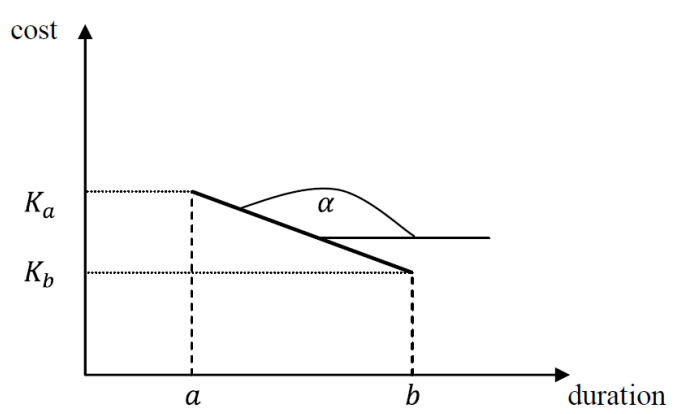

Fig. 1.

between them of which gradient is $\frac{K_{b}-K_{a}}{b-a}=\tan \alpha=-c$ where $c \geq 0$. These relationships are shown on Fig. 1 .

Remark 1 In case of connections between the activities we cannot talk about technical matter. But parameters $a, b$ and $c$ are also belonged to these arcs. If it is no use to define different cost levels then it is unnecessary to distinguish the normal and crash duration. So it is practical to use $a=b$ and $c=0$ parameters.

We can assign different technologies to one activity in the model. Their cost function is the same like the original one presented before.

The aim is to minimize the total cost of the project while meeting a given deadline.

\section{The standard cost function}

Here we only deal with applying two technological variants for an activity. The procedure with more variants is the same like this. Obviously the time parameters are different. Accordingly let denote them slow $(m)$ and rapid $(q)$ technologies. Contraction of their cost functions is on Fig. 2.

On Fig. 22. there are the slow and the rapid technology together which are apiece on Fig. 2a. and b. There are correspondences between these functions which let be assumptions henceforward.

$$
\begin{aligned}
& a^{q}<a^{m} ; b^{q}<b^{m} ; c^{q}>c^{m} \\
& a^{m} \leq b^{q} \\
& K_{b}^{q} \geq K_{b}^{m}+\left(b^{m}-b^{q}\right) \cdot c^{m}
\end{aligned}
$$

Remark 2 These assumptions are considered naturally. According to market conditions it is obvious that applying a faster technology effects higher cost level and increasing for a time unit. Overlap of the functions guarantees applying technologies which capacities are not too different.

The function on $\left[a^{m} ; b^{q}\right]$ section gives two values. As we are looking for minimum cost the higher value can never be determinative. So the function of rapid technology can be leaved on this section (Fig. 2d). However the function created this manner even has not one-to-one correspondence at $a^{m}$.
Tab. 1.

\begin{tabular}{llll}
\hline $\operatorname{arc}$ & $a$ & $b$ & $c$ \\
$(i, x)$ & $a^{q}$ & $a^{q}$ & 0 \\
$(x, i)$ & $-a^{q}$ & $-a^{q}$ & 0 \\
$(x, y)$ & 0 & $a^{m}-a^{q}-1$ & $\tau_{y z} \cdot c^{t c}+c^{q}$ \\
$(y, x)$ & $-\left(a^{m}-a^{q}-1\right)$ & 0 & 0 \\
$(y, z)$ & 0 & 1 & $c^{t c}$ \\
$(z, y)$ & -1 & 0 & 0 \\
$(z, j)$ & 0 & $b^{m}-a^{m}$ & $c^{m}$ \\
$(j, z)$ & $-\left(b^{m}-a^{m}\right)$ & 0 & 0 \\
$(i, y)$ & 0 & 0 & 0 \\
\hline
\end{tabular}

At meeting of technologies there are two cost levels ordered to only duration. Avoiding it let expand the technological change to one time unit (Fig.2p).

The change of technology happens on period $\left[a^{m}-1 ; a^{m}\right]$, of which gradient is derivable from data of the two cost functions.

$c^{t c}=\left[K_{b}^{q}+\left(b^{q}-\left(a^{m}-1\right)\right) \cdot c^{q}\right]-\left[K_{b}^{m}+\left(b^{m}-a^{m}\right) \cdot c^{m}\right]$

Remark 3 Depending on the two cost functions it is general that $c^{m}<c^{r}<c^{t c}$. It means that in case of change of technology we have to invest a higher capital to reach the cost level of rapid technology.

Remark 4 We apply maximal constraints at the activities, rarely at connections. They appear in the model in the opposite direction of the interpretation and having non positive time parameters. This manner the model is suitable for transform it exactly to MPM model applied in construction practice. So we have to use maximal constraint in case of every activity which parameters for the arc $(j, i)$ are

$$
\begin{aligned}
a_{j i} & :=-b_{i j} \\
b_{j i} & :=-a_{i j} \\
c_{j i} & :=0
\end{aligned}
$$

\section{The mathematical model}

Denote $[N, A]$ a directed graph, where $N$ is the set of nodes and $A$ is the set of arcs. There is only one start node $s$ and one end node $t$. There is a path in the network from node $s$ to every other node in the network. Directed graph contains no parallel arcs. On arcs let define $a_{i j}$ and $b_{i j}$ integers which have same sign and $a_{i j} \leq b_{i j}$ relation is true. Where $a_{i j}$ and $b_{i j}$ are non negative on section $\left[a_{i j} ; b_{i j}\right]$ let be the gradient of the function $-c_{i j} \leq 0$ integer. Otherwise let $c_{i j}=0$. Further let be $B \in A$ the set of arcs, where is given three $c_{i j}$ parameters according to (1) and (2). Expand $[N, A]$ by three further nodes $(x, y, z) \forall i j \in B$ place them between $i$ and $j$ as well as let $(i, y)$ a new virtual activity. Parameters of these new arcs are summarized in Table 1 and shown on Fig. 3 Marks come from Fig. 2. Maximal constraints are applied according to (3) which are prescribed in set $B$ further. 


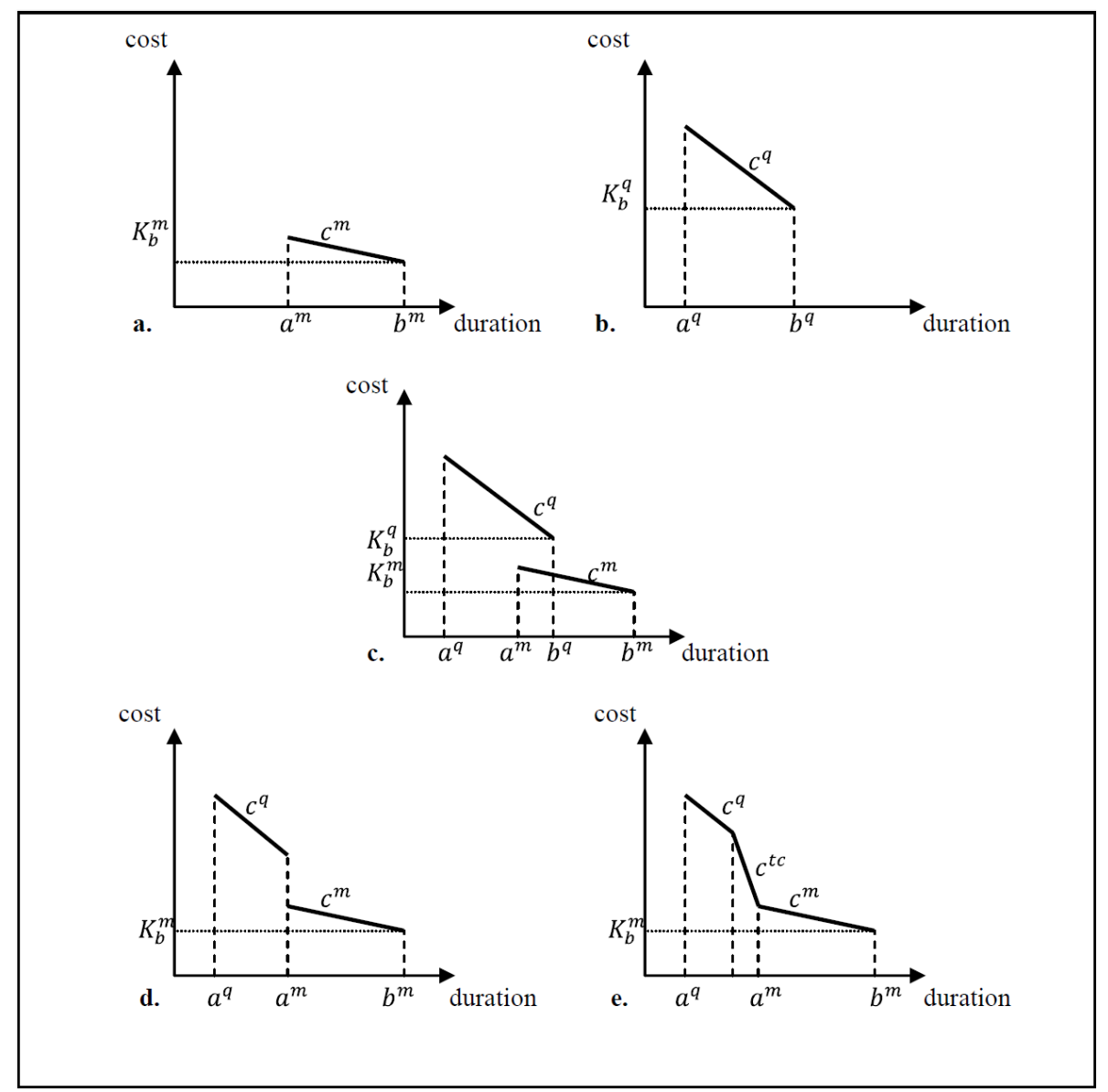

Fig. 2.

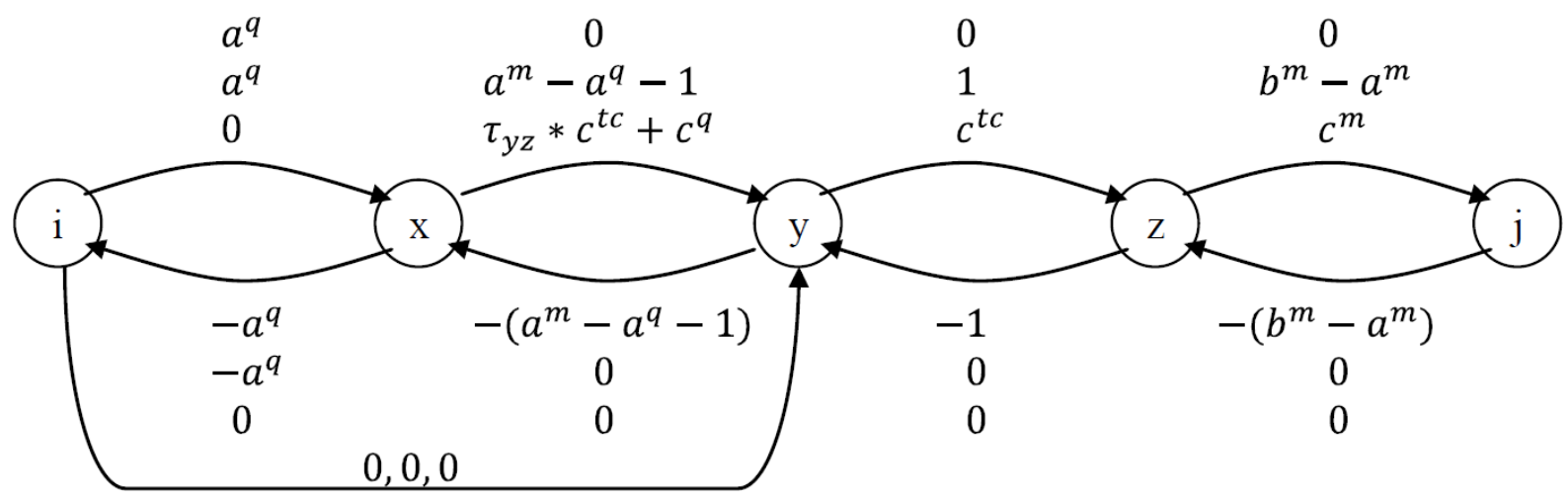

Fig. 3.

Let order $\mu_{i}$ values to every node of the digraph. The assumption is $\tau_{i j} \leq \mu_{j}-\mu_{i} \forall i j \in A$. The deadline of the project, i.e. the value of scheduling is $p$, where $p \geq \mu_{t}-\mu_{s}$. Let be $\mu_{s}=0$. Let complete $[N, A]$ digraph with $\operatorname{arc}(t, s)$, where $a_{t s}:=-p, b_{t s}:=0, c_{t s}:=0$. The network defined this way is signed by $[N, A]$. The aim is to find such $\tau$ and $\mu$ systems for every possible $p$, where

$$
\sum_{i j \in A}\left[K_{b_{i j}}+\left(b_{i j}-\tau_{i j}\right) \cdot c_{i j}\right]
$$

summation is minimal.

Primal problem. Given $[N, A]$ digraph with $a_{i j}, b_{i j}$ and $c_{i j} \geq$
0 integers for $\forall i j \in A$ and $p$ integer. Find $\mu_{i} \forall i \in N$ and $\tau_{i j} \forall i j \in A$ that

$$
\begin{gathered}
\sum_{i j \in A}\left[K_{b_{i j}}+\left(b_{i j}-\tau_{i j}\right) \cdot c_{i j}\right] \rightarrow \text { minimal that is } \\
\sum_{i j \in A} c_{i j} \cdot \tau_{i j} \rightarrow \text { maximal }
\end{gathered}
$$


Tab. 2. Chart 2

\begin{tabular}{lllll}
\hline class & $\mu_{j}-\mu_{i}$ & $f_{i j}$ & $r_{i j}$ & $r_{j i}$ \\
\hline I & $\mu_{j}-\mu_{i} \geq b_{i j}$ & $f_{i j}=0$ & $r_{i j}=0$ & $r_{j i}=0$ \\
II & $a_{i j} \leq \mu_{j}-\mu_{i} \leq b_{i j}$ & $f_{i j}=c_{i j}$ & $r_{i j}=0$ & $r_{j i}=0$ \\
III & $a_{i j}=\mu_{j}-\mu_{i}$ & $f_{i j} \geq c_{i j}$ & $r_{i j}=\infty$ & $r_{j i}=f_{i j}-c_{i j}$ \\
IV & $\mu_{j}-\mu_{i}=b_{i j}$ & $f_{i j} \geq 0$ & $r_{i j}=c_{i j}-f_{i j}$ & $r_{j i}=f_{i j}$ \\
$V$ & $a_{i j}=\mu_{j}-\mu_{i}=b_{i j}$ & $f_{i j} \geq 0$ & $r_{i j}=\infty$ & $r_{j i}=f_{i j}$ \\
VI & $a_{i j}=b_{i j}=0<\mu_{j}-\mu_{i}$ & $f_{i j} \geq 0$ & $r_{i j}=0$ & $r_{j i}=f_{i j}$ \\
\hline
\end{tabular}

subject to

$$
\begin{array}{r}
\tau_{i j} \leq \mu_{j}-\mu_{i} \quad \forall i j \in A \\
\tau_{i j} \leq b_{i j} \quad \forall i j \in A \\
\tau_{i j} \geq a_{i j} \quad \forall i j \in A \\
\mu_{s}=0 \\
-p \leq \mu_{s}-\mu_{t}
\end{array}
$$

Corresponding to the primal problem a dual problem is established here. Let us consider $[N, A, h]$ network where $h_{i j}=\infty$ if $i j \in A$ and 0 otherwise.

Dual problem. Find a flow $f_{i j}$ for $\forall i j \in A$ from $s$ to $t$ on network $[N, A, h]$, that

$$
\begin{gathered}
\sum_{\substack{i j \in A \\
f_{i j}<c_{i j}}}\left(c_{i j}-f_{i j}\right) \cdot b_{i j}- \\
-\sum_{\substack{i j \in A \\
f_{i j}>c_{i j}}}\left(f_{i j}-c_{i j}\right) \cdot a_{i j} \rightarrow \text { minimal }
\end{gathered}
$$

subject to

$$
\sum_{i j \in A} f_{i j}-\sum_{j i \in A} f_{j i}=0 \quad \forall i \in N
$$

The relationship between primal and dual problems is shown in next lemma.

Lemma 1 Every $\mu$ and $\tau$ vector fulfiled (4) and $f$ flow fulfiled (5) achieve the next relation

$$
\begin{gathered}
\sum_{i j \in A} c_{i j} \cdot \tau_{i j} \leq \sum_{\substack{i j \in A \\
f_{i j}<c_{i j}}}\left(c_{i j}-f_{i j}\right) \cdot b_{i j}- \\
-\sum_{\substack{i j \in A \\
f_{i j}>c_{i j}}}\left(f_{i j}-c_{i j}\right) \cdot a_{i j}
\end{gathered}
$$

Proof. It agrees with deduction in paper of Klafszky [1].

Optimality criteria. The enough assumption for equality of the aim functions is existing such $f$ flow that if $\tau_{i j}>0$ and

$$
\begin{aligned}
& \text { 1. if } \tau_{i j}<\mu_{j}-\mu_{i}, \quad \text { then } \quad f_{i j}=0 . \\
& \text { 2. if } \tau_{i j}<b_{i j}, \text { then } f_{i j} \geq c_{i j} . \\
& \text { 3. if } \tau_{i j}>a_{i j}, \text { then } c_{i j} \leq f_{i j} .
\end{aligned}
$$

It is presented graphically on Fig. 4.

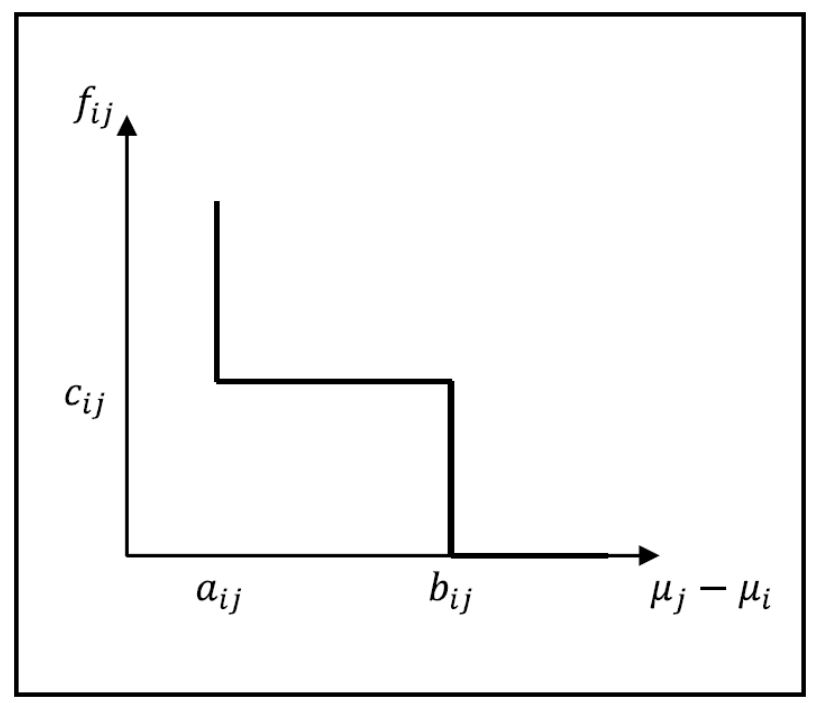

Fig. 4.

It seems on the figure that value $\tau_{i j}$ is not reducable under $b_{i j}$ while $f_{i j}<c_{i j}$. The algorithm continually rise the amount of flow so the arcs become impregnated in order to their value $c_{i j}$. In this way it is sure that reducing of durations is possible on arc with the current lowest cost intension.

According to optimality criteria we can order arcs into six classes. For dual problem let define $\hat{A}$ the set of arcs as if $\exists i j \in$ $A$, then $i j, j i \in \hat{A}$. Based on it let define $[N, \hat{A}, r]$ residual capacity network, where $r$ capacity limit is changable according to the class of arc (Look Table 2).

Durations on fullness arcs in $[N, \hat{A}, r]$ can change based on Table 3 .

If $\tau_{y z}(y, z) \in B$ is reduced, i.e. technological change occurs, $c_{x y}$ is also changed with it. At this moment flow level is $c_{y z}\left(=c^{t c}\right)$ based on Table 2. States are on Fig. 5 before and after change. It shows that after technological change the flow on $(x, y)$ is not fulfilled conditions (7). 


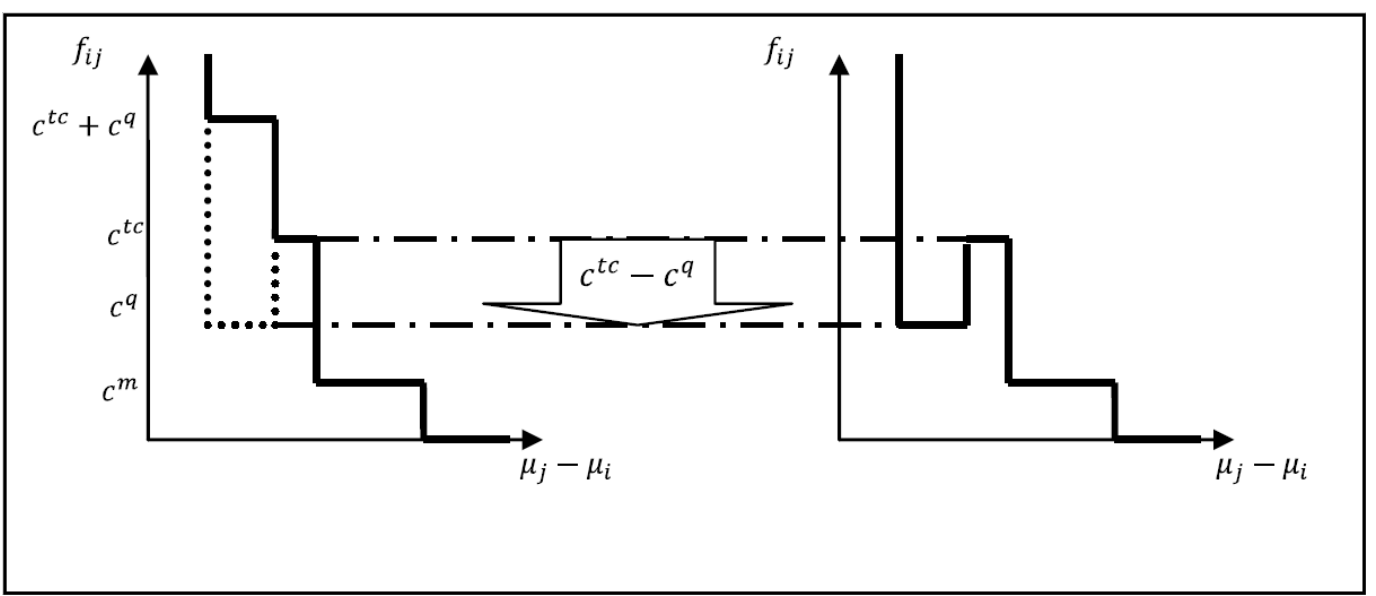

Fig. 5.
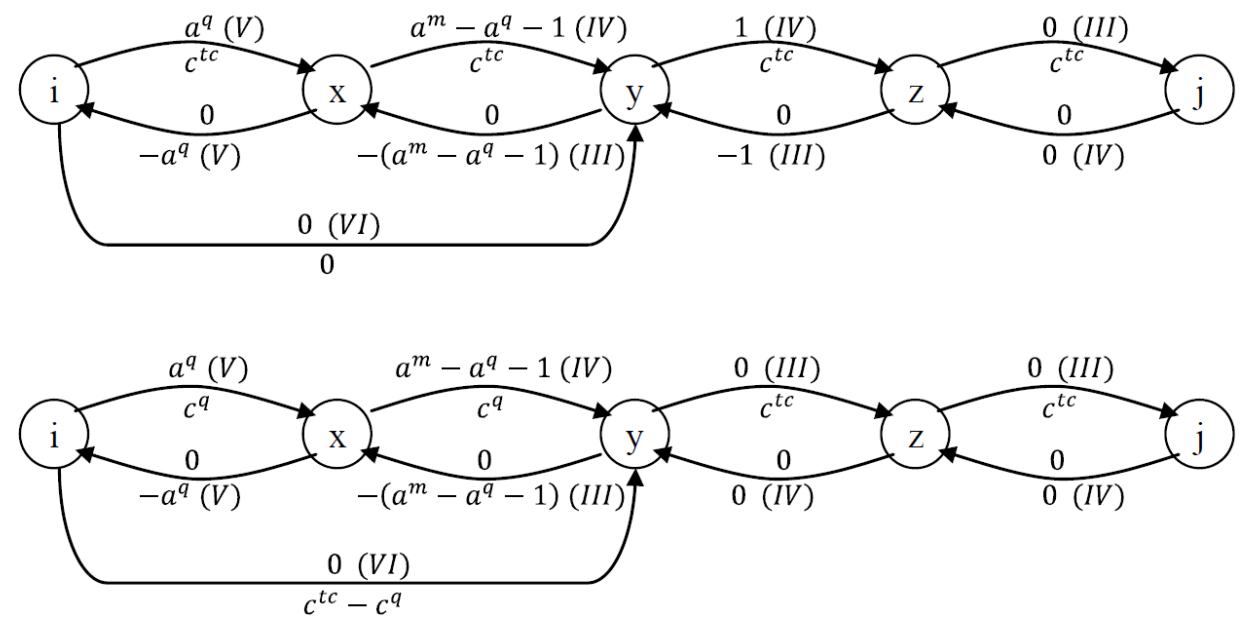

Values on arcs:

$$
\begin{aligned}
& \tau_{i j} \text { (class) } \\
& \text { flow level }
\end{aligned}
$$

Fig. 6.

1. Engineering of $[N, A]$ digraph based on Chart 1. and Fig. 3.

2. $\tau_{i j}=\max \left\{\left|b_{i j}\right|,\left|a_{i j}\right|\right\} \forall i j \in A$

3. Determination of vector $\mu$ based on (3).

4. Classification of arcs based on Chart 2 .

5. Building up $[N, \hat{A}, r]$ residual capacity network based on the classification.

6. On $[N, \hat{A}, r]$ determination of vector $f$ cut $v$ based on maximal flow minimal cut algorithm and (4).

7. If $\nexists v$, then STOP.

8. On $[N, \hat{A}, r]$ determination $\forall i j \in v \boldsymbol{\delta}_{\boldsymbol{i j}}$ based on Chart 3 .

9. $\delta=\min \left\{\boldsymbol{\delta}_{i j}, i j \in v\right\}$

10. $\mu_{i}:=\mu_{i}-\delta \forall i \in T$

11. If technological change occurs in $v$, then flow direction based on (7).

12. $\tau_{i j}=\min \left\{b_{i j}, \mu_{j}-\mu_{i}\right\} \forall i j \in A$

13. Back to step 4.

Fig. 7. 
Tab. 3. Chart 3

\begin{tabular}{llll}
\hline class & fullness flow level & $\mu_{j}-\mu_{i}$ reduction & $\mu_{j}-\mu_{i}$ rise \\
\hline I & 0 & $\mu_{j}-\mu_{i}-b_{i j}$ & no limited \\
II & $c_{i j}$ & $\mu_{j}-\mu_{i}-a_{i j}$ & $-\left(\mu_{j}-\mu_{i}-b_{i j}\right)$ \\
III & $c_{i j}$ & impossible & $-\left(\mu_{j}-\mu_{i}-b_{i j}\right)$ \\
IV & $c_{i j}$ & $\mu_{j}-\mu_{i}-a_{i j}$ & impossible \\
V & 0 & impossible & no limited \\
VI & $f_{i j}$ & $\mu_{j}-\mu_{i}$ & no limited \\
\hline
\end{tabular}

\section{The algorithm (Fig. 7 )}

Therefore we have to take a flow directing as follows.

$$
\begin{gathered}
f_{i x}=c^{q} \quad f_{x y}=c^{q} \quad f_{y z}=c^{t c} \\
f_{z j} \leq c^{q}\left(=c^{t c}\right) \quad f_{i y}=c^{t c}-c^{q}
\end{gathered}
$$

Flow direction shown on Fig. 6influences locally only on the arc group belonged to the activity shown on Fig. 3 . Now flow level on $(x, y)$ is fulfilled optimality criteria after its capacity change.

$T$ is the set of nodes which are not accessible from $s$ if arcs in $v$ are deleted.

\section{Example}

There is a schedule on Fig. 8 On arcs $(1,2)$ and $(3,4)$ there are double parameters as data of a slow and a rapid technology in order $a_{i j}, b_{i j}, c_{i j}$ and $K_{b_{i j}}$. According to (3) maximal constraints are assigned to the activities which have zero initial cost level. The arcs $(1,3)$ and $(2,4)$ are simplified connections based on Remark 1. Their value $K_{b_{i j}}$ are disinterested in point of the task. Firstly let determine the cost of technological changes at

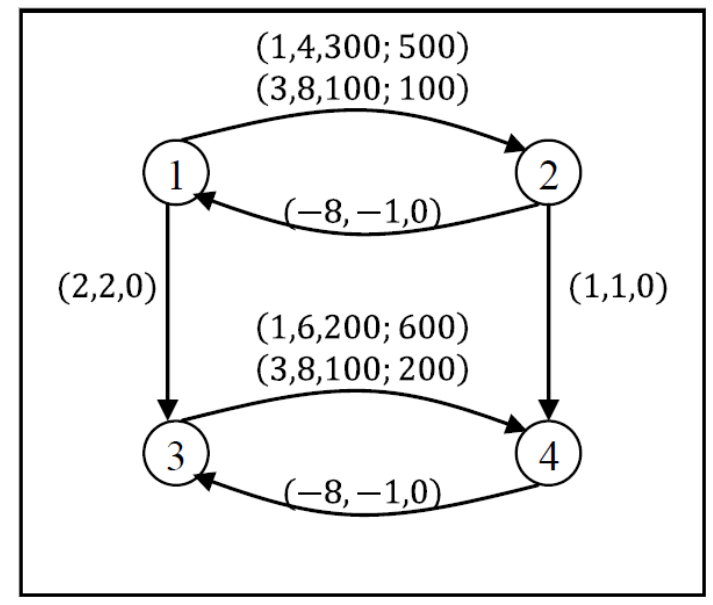

Fig. 8.

the activities based on (2).

$$
\begin{array}{r}
c_{12}^{t c}=[500+(4-(3-1)) \cdot 300]- \\
{[100+(8-3) \cdot 100]=500} \\
c_{34}^{t c}=[600+(6-(3-1)) \cdot 200]- \\
{[200+(8-3) \cdot 100]=700}
\end{array}
$$

cost parameters based on Fig. 3. The first feasible solution is on Fig. 10 A. Here $f_{i j}=0 \quad \forall i j \in A$. Classification of arcs is on Fig. 10p. and residual capacity network belonged it is on Fig. 10. Maximal flow is on Fig. 10d. The new flow (currently $f=100$ ) is on thick arcs. Based on it fullness arcs on the residual capacity network are also emphasised by thick line which determine the $v$ minimal cut. According to Table 3 we can determine the possible changes in potentials in $v$.

$$
\begin{array}{r}
\delta_{24}=10-8-1=1 \\
\delta_{104}=10-5-0=5 \\
\delta_{410=-(5-10-0)}=5 \\
\delta=1
\end{array}
$$

On Figs. 11,14 there are shown the following steps in a similar manner without notes.

By cutting the arc $(9,10)$ the technological change occurs so we have to take a flow direction shown on Fig. 12.

By cutting the arc $(6,7)$ the technological change occurs so we have to take a flow direction shown on Fig. 13 .

In the residual capacity network on Fig. 14, there exists $P(s, t)$ path where $r_{i j}=\infty \forall i j \in P(s, t)$ so this is the end of the algorithm.

\section{Run-time of the algorithm}

Practically the algorithm is by analogy with method in work of Klafszky [11]. The main difference is at the creation of the network model. Thus the base of comparing is this feature. Let be $n$ the number of original set $N$ and $m$ the number of original set $A$. So the expansions by creation of the model are not numbered here. For simplification let assume exactly two technologies in set $B$. Let $q$ the number of set $B$.

In case of the original algorithm for determine the minimum cost for a given deadline we have to examine all the variation of technologies. It means $2^{q}$ variations.

In spite of this the generalized algorithm examines all technologies simultaneously. Although the network is bigger a little, namely there are

$$
\begin{aligned}
& n+3 q \text { nodes } \\
& m+(2 \cdot 3+1) \cdot q \text { arcs. }
\end{aligned}
$$

And we have to take flow directions which modify two arc parameters only. The algorithm uses the maximal flow minimal cut problem iteratively. Applying Edmonds Karp algorithm its run-time is $O\left(\mathrm{~nm}^{2}\right)$. In case of the original and the generalized version it means

$$
O\left(2^{q} \cdot n m^{2}\right) \leftrightarrow O\left((n+3 q) \cdot(m+7 q)^{2}\right)
$$

Let engineer the $[N, A]$ network according to Table 1 and Fig. 3 (Fig. 9. On arcs $(5,6)$ and $(8,9)$ there are shown both of the
It is visible that at the generalized algorithm $q$ performs as factor while at the original one it is index. It causes exponential 
Fig. 9.

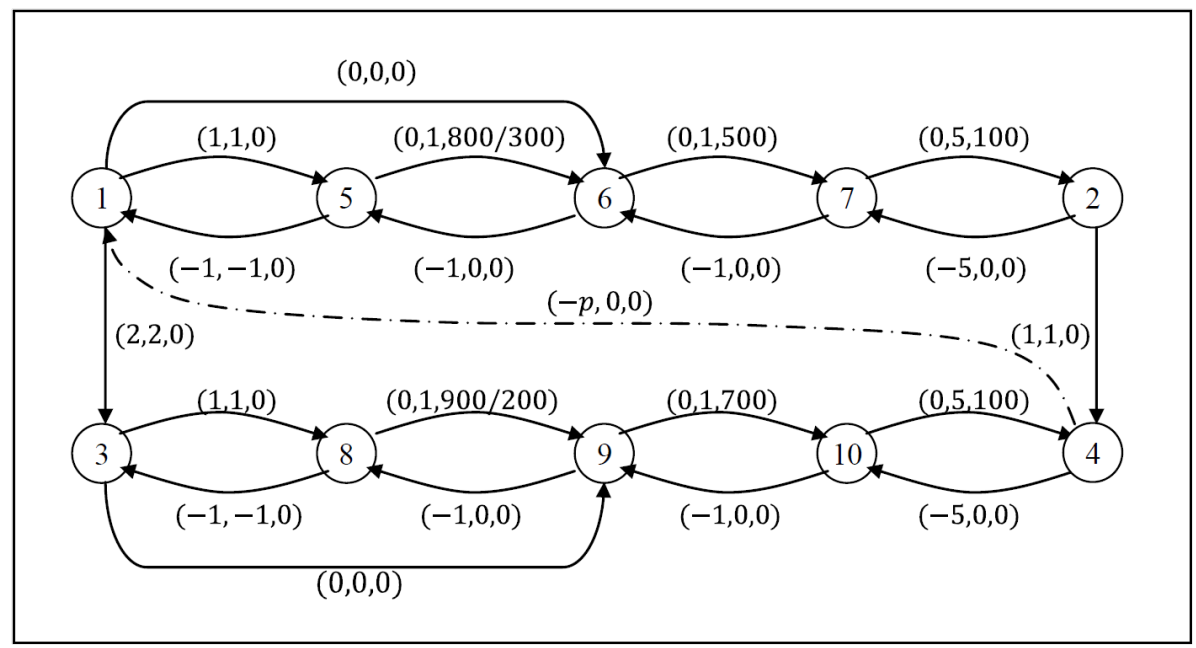

Fig. 10.

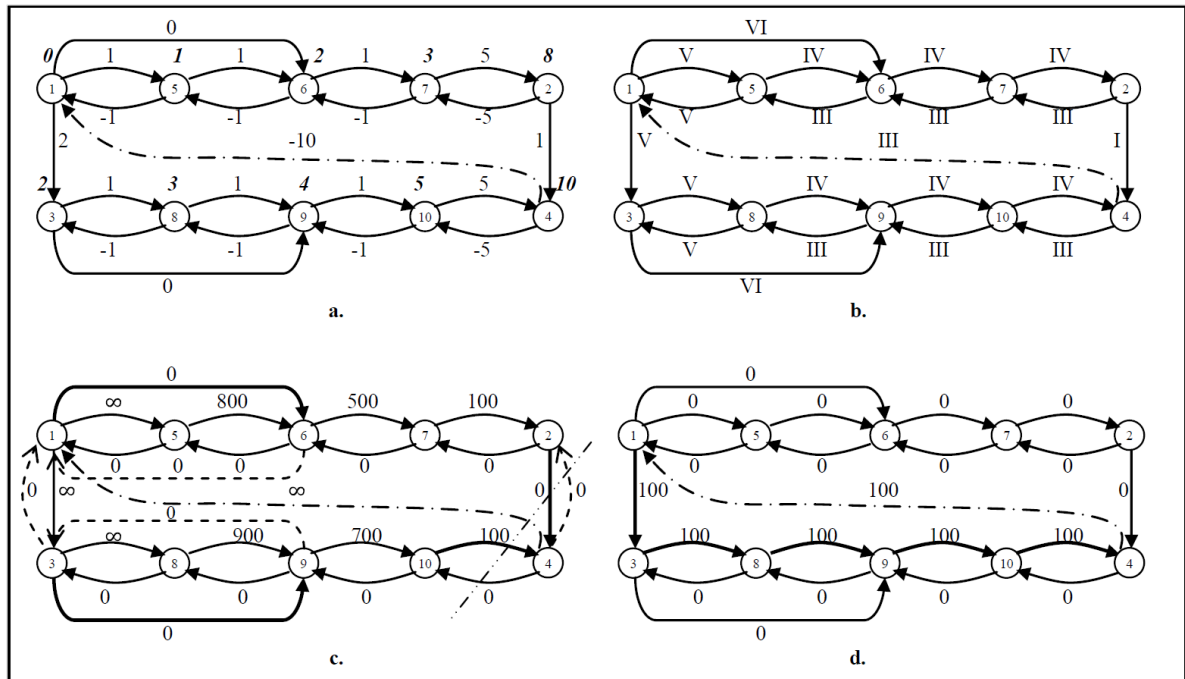

Fig. 11.
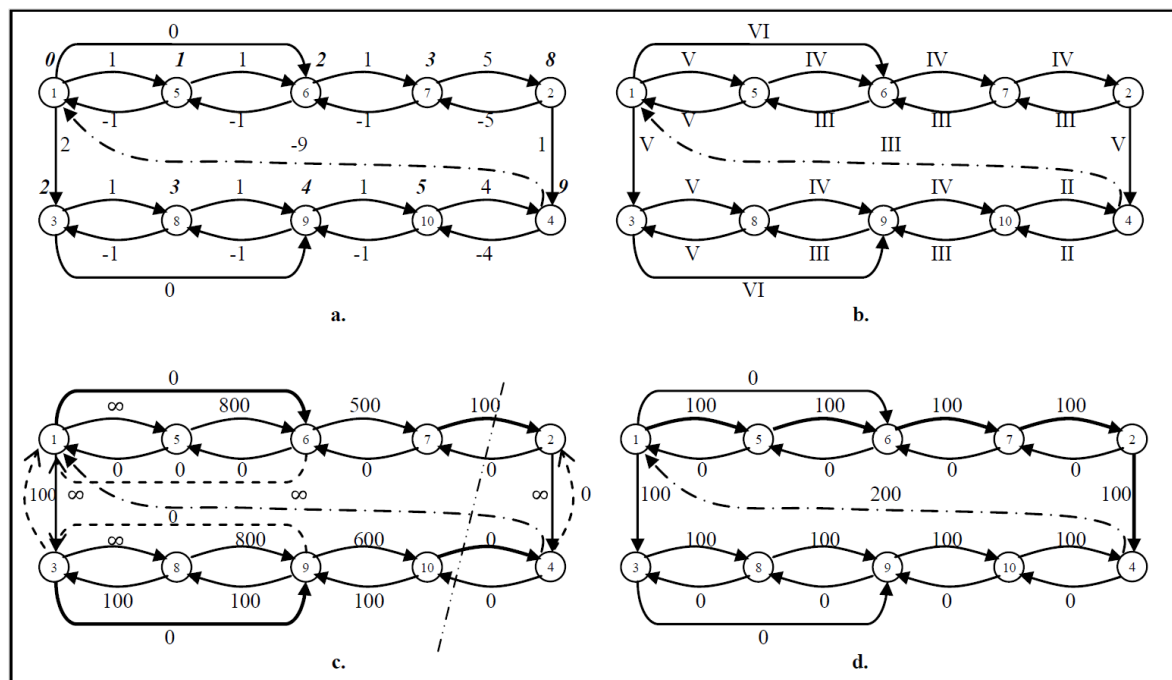

$$
\begin{aligned}
\delta_{72}=8-3-0 & =5 \\
\delta_{104}=9-5-0 & =4 \\
\delta_{27}=-(3-8-0) & =5 \\
\delta_{410}=-(5-9-0) & =4 \\
\delta & =4
\end{aligned}
$$


Fig. 12.

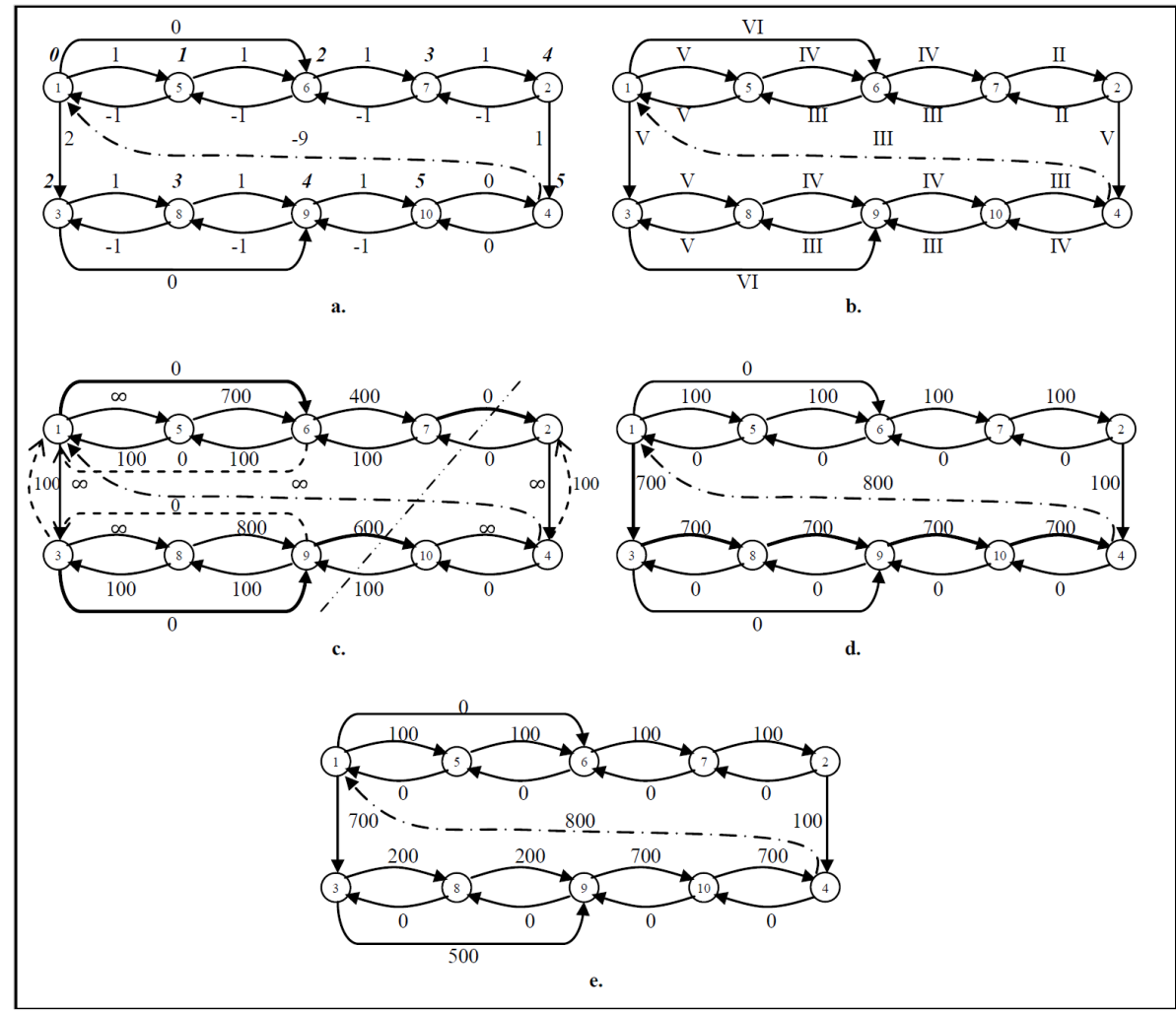

$$
\begin{aligned}
\delta_{72}=4-3-0 & =1 \\
\delta_{910}=5-4-0 & =1 \\
\delta_{27}=-(3-4-0) & =1 \\
\delta_{109}=-(4-5-0) & =1 \\
\delta & =1
\end{aligned}
$$

run-time accession by rise $q$. Otherwise in case of the generalized algorithm this accession is only polynomial. So the more technological variants we use in scheduling the more efficient the generalized algorithm is. Further let consider that $\operatorname{arcs}(i, x)$ and $(i, y)$ are never determinative in point of maximal flow minimal cut problem.

\section{References}

1 Ahuja R K, Magnanti T L, Orlin J B, Network flows: Theory, Algorithms, and Applications, Prentice Hall, 1993.

2 Csordás H, Mályusz L, A network flow algorithm for time-cost tradeoffs with technological decision, VII. International Conference Organization, Technology and Management in Construction (Zadar, 2006).

3 Fulkerson R D, A network flow computation for project cost curves, Management Science 2 (Jan 1961), no. 2, 167-168.

4 Hajdú M, An algorithm for solving the cost optimization problem in precedence diagramming method, Periodica Polytechnica ser. Civil Engineering 37 (1993), no. 3, 231-247.

5 Hajdú M, Klafszky E, An algorithm to solve the cost optimization problem through an activity on arrow type network (CPM/cost problem), Periodica Polytechnica ser. Architecture 37 (1993), no. 1-4, 27-40.

6 Hajdú M, PDM Time Cost Trade Off: Activities Are Splittable or NonSpittable, Optimization 38 (1996), 155-171.

7 Mályusz L, A költségtervezési „Time-cost trade-off” feladat általánositása és megoldása, Alkalmazott Matematikai Lapok 21 (2004), 365-377.
8 Monoton Növekedö költségfüggvényü tevékenységek alkalmazása a költségtervezési „Time-cost trade-off” feladatban, Alkalmazott Matematikai Lapok 22 (2005), 199-213. (Applicaton of tasks with increasing cost functions in Time-cost trade-off problems).

9 Kelley J E, Critical Path Planning and Scheduling: Mathematical Basis, Operation Research 9 (1959), no. 3.

10 Kelley J E, Walker M R, Critical Path Planning and Scheduling, Proc. the Eastern Joint Computer Conference (Boston, 1959).

11 Klafszky E, Hálózati folyamok (Network flows), Budapest, 1969. 
Fig. 13.
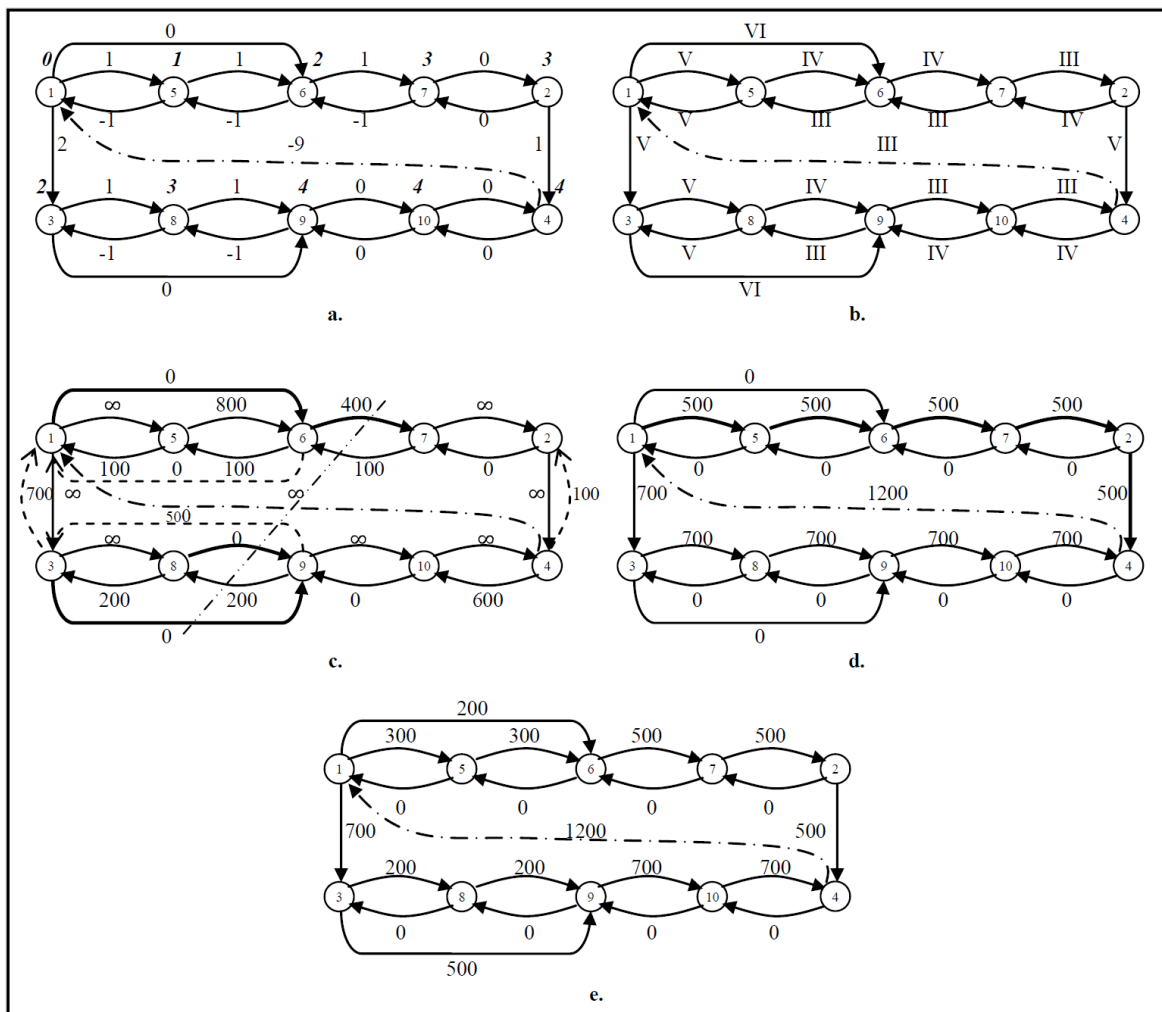

$$
\begin{aligned}
\delta_{67}=3-2-0 & =1 \\
\delta_{89}=4-3-0 & =1 \\
\delta_{76}=-(2-3-0) & =1 \\
\delta_{98}=-(3-4-0) & =1 \\
\delta & =1
\end{aligned}
$$

Fig. 14.

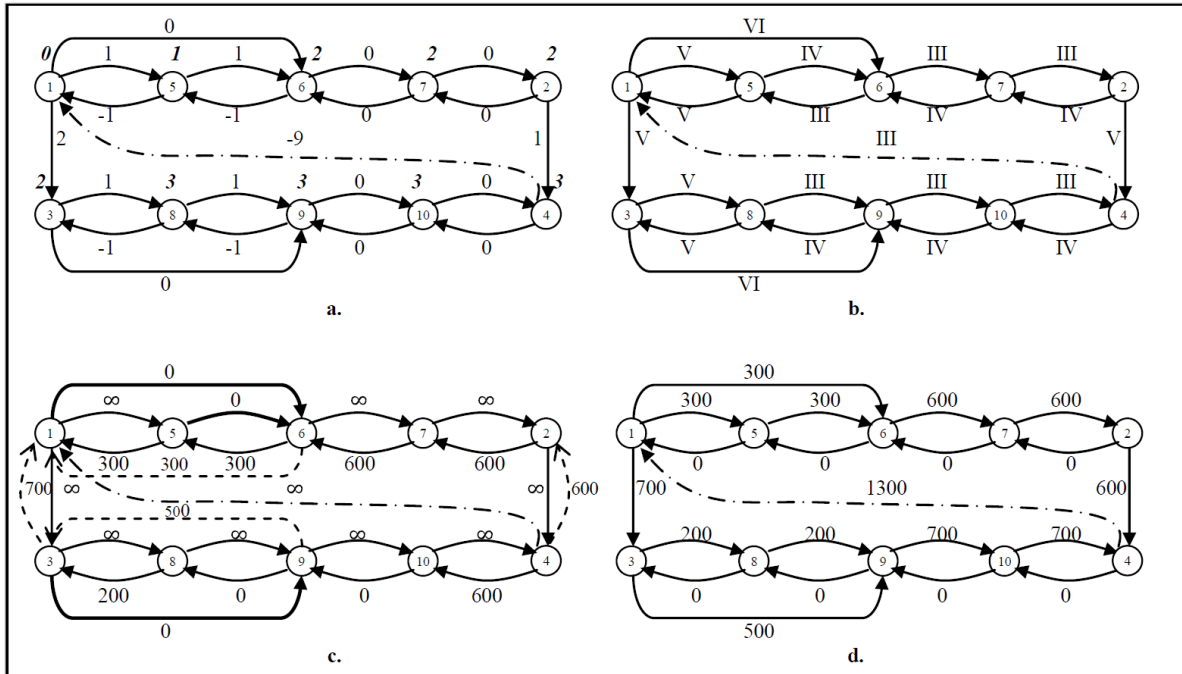

